\title{
"The Facts in the Case of M. Valdemar": Undead Bodies and Medical Technology
}

\author{
Sarah O'Dell ${ }^{1,2}$ D \\ Published online: 2 September 2019 \\ (C) Springer Science+Business Media, LLC, part of Springer Nature 2019
}

\begin{abstract}
This paper examines the relationship between medical technology and liminal states of "undeath" as presented in "The Facts in the Case of M. Valdemar" and the real-life case of Jahi McMath, who was maintained on life support for over four years following a diagnosis of brain death. Through this juxtaposition, "Valdemar" comes to function as a modern fable, an uneasy herald of medical technology's potential to create liminal states between life and death. The ability to transgress these boundaries bears a cost, however: both Valdemar and Jahi McMath lose the autonomy to direct their respective narratives. Yet, their utterances "from beyond the grave" highlight the precarious nature of their position and the ethical concerns therein. Poe's literary performance of "undeath" therefore serves to caution real-life cases in which life support is used to sustain an individual reported to be brain-dead. Such application of life-sustaining technology complicates the fundamental binary of life/death, allowing its subjects to resist textual closure. Even as Poe's work represents an imaginative interrogation of the scientific enterprise, this nineteenth-century story holds a mirror to contemporary medical practice, inviting a reconsideration of the ethics, language, and power relations surrounding the fraught relationship between death and medical technology.
\end{abstract}

Keywords Edgar Allan Poe - Gothic literature · Jahi McMath · Definitions of death · Medical technology

\section{Introduction}

An individual is seriously ill, to the point of imminent death. Someone intervenes, and death is suspended; the afflicted appears stable. This condition continues for a considerable amount of time - months - without any serious improvement in health. Even as the patient's physical frame remains intact, the boundaries between death and life begin to blur: his consciousness

Sarah O'Dell

sodell@hs.uci.edu

1 Department of English, University of California Irvine, Irvine, California, USA

2 University of California Irvine School of Medicine, Irvine, California, USA 
falls into question, and he is only able to move under the volition of another. Following a pronunciation of death, certain signs of life persist. Is he still "dying"? Is the "treatment" prolonging life, or merely bestowing the appearance of life? Is he somehow hovering between life and death, unable to claim a post among the dead or the living? Eventually, the intervention is ceased. Any previous confusion is quick to dissipate: the individual has obviously passed. The process of decay is clear and dramatically so.

What does it mean to die? Can an individual be defined as dead, yet continue to live, however tenuous the thread that aligns them with the living? Is it possible to die twice? At first blush, this scenario bears the mark of Gothic fiction: a preoccupation with death, the representation of "undeath," as well as the trappings of mystery and fear. And yet, the moniker of "patient" and the invocation of life-sustaining intervention align this story with real-life situations of end-of-life care, especially in the wake of today's advanced medical technology.

Despite the appearance of the actual, this particular story is a fiction: "The Facts in the Case of M. Valdemar," penned by Edgar Allan Poe in 1845. The intervention in question is mesmerism, the forerunner of modern-day hypnotism, administered by the amateur mesmerist and narrator of the tale, only identified (perhaps winkingly) as "P." The patient, M. Ernest Valdemar, who is dying of consumption, gives consent to be mesmerized "in articulo mortis," that is, at the point of death. The mesmerist's intention for this experiment is not only to observe how the act of dying alters the powers of mesmerism but also to gauge "to what extent, or for how long a period, the encroachments of Death might be arrested by the process" of the trance (Poe 1978, 1233). As a result, Valdemar is suspended in an apparent state of undeath for seven months. His final passing only occurs once he is released from the mesmeric influence, at which point his body rots away in the space of an instant.

Not only does the inherent ambiguity of the tale align it with contemporary discussions surrounding the nature of human death, but the use of mesmerism to arrest death-when understood as a nineteenth-century medical technology — also bears a striking resemblance to possible uses of twenty-first century life support. In presenting mesmerism as a medical technology, Poe forces both mesmerism and our understanding of death to their natural, or even unnatural, limits. Crucially, "Valdemar" ultimately demonstrates the ability of technology to change the human, inviting the twenty-first century reader to re-examine her own assumptions regarding the use of life-sustaining medical technology in a death-prolonging capacity.

Despite the gruesome qualities of Poe's fiction, its central elements bear a marked resemblance to a recent occasion of disputed brain death: the unprecedented case of Jahi McMath, a thirteen-year-old girl who, following a 2013 diagnosis of brain death, remained under advanced life-support for over four years until her final passing in July 2018. While the contemporary debate surrounding the authenticity of "Valdemar" has long been put to rest, Poe's tale still demands notice as a conceptualization of death. Conversely, Jahi's tale continues to generate its own controversy: the case gained a foothold in the popular imagination, and the legal battle over her status in the time between her two "deaths" is far from over.

While I recognize that reading Jahi's story in parallel with Poe's nineteenth-century experiment of the imagination demands the utmost care and sensitivity, there is much to be gained from such a reading. The juxtaposition of the two "cases" heightens the disruptive nature of each narrative, all the while underlining the practical and philosophical implications - and lingering questions - that adhere to each. "Valdemar" comes to function as a modern fable, an uneasy herald of medical technology's potential to create liminal states that hover between life and death. Of course, the ability to transgress these boundaries bears a heavy cost: both Valdemar and Jahi McMath lose the autonomy to direct their respective 
narratives. Yet, they do not remain silent. Their utterances "from beyond the grave," while limited, come to highlight the precarious nature of their position and the ethical concerns therein. Poe's literary performance of "undeath" and the concomitant mechanization of the individual therefore serve to caution real-life cases in which life support is used to sustain an individual reported to be brain-dead. Such application of life-sustaining technology complicates the fundamental binary of life/death, allowing its subjects to resist textual closure. Even as Poe's work represents an imaginative interrogation of the scientific enterprise, this nineteenth-century story holds a mirror (however ghastly) to contemporary medical practice, inviting a reconsideration of the ethics, language, and power relations surrounding the fraught relationship between death and medical technology.

\section{Technology and the human}

Before gazing through this looking-glass, it is helpful to contextualize briefly mesmerism as a medical technology of the nineteenth century. The eponymous practice, also referred to as animal magnetism, was first developed by the Austrian physician Franz Mesmer in the eighteenth century. Mesmer promoted the idea of an invisible and ubiquitous "animal fluid" that, if properly manipulated, could produce bodily cures (Mills 2013, 323). Pamphlets advertising mesmerism stressed the role of the physician, who, through imposing his will on a receptive mind, could "elicit striking effects" both physical and mental (Mills 2013, 324). The mesmeric trance was characterized by a triangular relationship between the trance state, patient, and physician, and physician-patient repartee was thought to influence the success of the encounter (Willis 2006, 96). By the 1830s, mesmerism was widely practiced by physicians in both the United States and Britain, yet it never received full acceptance in mainstream science, instead retaining the faint suggestion of malpractice (Willis 2006, 115). Although mesmerism served as a forerunner of modern-day hypnotism, it was often regarded as supernatural, even diabolical, and viewed with skepticism. Regardless, this suspicion was insufficient to deny mesmerism a place within the scientific hierarchy; there was no clear seat of authority from which mesmerism could be excluded from medical practice (Willis 2006, 10).

Fascination with the effects of the trance state on consciousness was partly due to the practice's apparent ability to blur the lines between life and death, challenging the boundaries of human capability even as mesmerism itself subsisted on the boundaries of mainstream science. Chauncy Hare Townshend's Facts in Mesmerism, a well-known apologetic for the practice, provided Poe with the technical details of the mesmeric trance; indeed, Sidney E. Lind has demonstrated that Poe directly transcribed portions of Townshend's Facts into his own literary hoax of "Facts" (Lind 1947). While Poe had a sophisticated knowledge of animal magnetism, his interest in the practice is largely due to its supposed ability to dissolve boundaries between the material and the spiritual. Martin Willis comments:

Poe is more interested in the effects of new scientific practices on the human body and mind than in the precise details of mesmerism [in and of themselves]. He feels able to alter the effects in order to illuminate, and give primacy to, the human at the center of his experiments. $(2016,120-1)$

Poe's tale therefore both plays on and interrogates Townshend's insistence that through mesmerism, "man can act upon man, at all times and almost at will ... the action of man upon the imagination may be reduced to an art" $(1841,12)$. 
The ability of humans to act upon each other, especially in the realm of death and dying, provides the impetus for the events of Poe's Gothic tale. When the trance is initially established at Valdemar's deathbed, certain signs of life diminish: his breathing calms, soon becoming "scarcely noticeable," his pulse is "imperceptible," and his limbs are "as rigid and as cold as marble" (1978, 1238). The mesmerist is better able to control Valdemar's movements, likely facilitated by the patient's weakened will. Even while Valdemar clings to life, those present anticipate that he will pass away within minutes, the discomfort of his dissolution made peaceful by the trance state. Yet, the mesmerist insists - contrary to the desires of the physicians - on continuing his communication with Valdemar, eliciting that scene "so hideous beyond conception." Valdemar pronounces himself deceased, and several signs of life vanish: mesmerism is no longer sufficient to manipulate his limbs, and "an attempt to draw blood from the arm failed," likely indicating circulatory failure. Upon further questioning, he appears to attempt a reply, but he lacks "sufficient volition" (1241).

Valdemar is spared the finality of death, but he is also denied the fullness of life. His loss of self-sovereignty is complete, and he will never again move his limbs by his own volition. While death is not evaded, it is arrested: mesmerism is sufficient to suspend the organic process of decay. The mesmerist's failure to release Valdemar from the trance - and indeed, his refusal to cease the almost-psychic imposition of his own will on the sufferer-ultimately prolongs Valdemar's experience of death, magnifying an otherwise transitory state of undeath into the space of seven months. Presumably, the narrator does so for the sake of the "experiment," dehumanizing Valdemar and reducing him to a curious subject of daily calls with "medical and other friends" (1241). The futile "treatment" of mesmeric trance presents a clear, and even overwhelming, challenge to Valdemar's autonomy: even as he forcefully declares the reality of his own death, attempts are made to revive him.

By tethering Valdemar's consciousness to a failed body, mesmerism relegates him to the status of a machine-like object, subject to the will of the mesmerizer. Marin Willis has previously identified this tendency toward mechanization in a number of Poe's tales, noting cases in which characters' ways of presenting to the world is artificial, mediated by the technological yet below the threshold of immediate observation. "The Man That Was Used Up" presents another such case, relating the situation of a "truly fine-looking fellow, Brevet Brigadier General John A. B. C. Smith” (Poe 1856, 315). General Smith's physical appearance is decorated with lavish praise by the unnamed narrator, who commends his entire frame, from his possession of the "handsomest pair of whiskers under the sun" to his lower limbs, the "ne plus ultra of good legs" (316). When the narrator bursts in on the General while dressing, he realizes the horrible truth: his host is composed of artificial parts; he is "the man who was used up," dismantled by the injuries of war. Only after the General is literally assembled before him does the initially "large and exceedingly odd looking bundle of something" (323) become recognizable as the handsome and human General.

This "replacement of the human body with a mechanical substitute," Willis argues, underscores the "cultural significance of a society that is allowing the machine to act as a substitute for the human without this surrogacy ever being visible" (2006, 98-99). Even as mesmerism is characterized by the invisible forces of animal magnetism, the effects of modern life support can also be obscured from view. This is not due to any physical invisibility of the apparatus but instead due to the machine's ability to mask otherwise fatal neurological damage. In cases of brain death, for example, machines replace critical activities (e.g. breathing) that can no longer be accomplished by the individual. A ventilator keeps the organs oxygenated, and artificial nutrition proves cells with necessary energy. So nourished, the heart's intrinsic 
pacemaker allows it to continue beating even with a lack of neurological input, and the chest continues to rise and fall. A body can present in this way even if the brain was completely liquified. By disguising the physiological reality of the individual's fatal injury, new problems in diagnosing death are furnished by technological development.

\section{Who speaks? authority and narrative in "Valdemar"}

Even as mesmerism allows E. M. Valdemar to inhabit the threshold between life and death, "Valdemar" plays upon the power of scientific reporting to blur the line between fact and fiction, as John Tresch suggests, "enabl[ling] a double reading that held the tale's veracity in suspension even beyond the grotesque final collapse" (2016, 888). Upon its publication, many received "The Facts in the Case of M. Valdemar" as a valid medical report; John Henry Ingram notes that Poe was "overwhelmed with inquiries" regarding the tale's status as fact or fiction $(1880,276)$. An 1846 reprint of the story in Britain even included an assertion that it contained a "plain recital of facts" widely accepted in the United States (Mills 2013, 327). Robert H. Collyer, a well-known proponent of mesmerism and founder of Mesmeric Magazine, noted the "great sensation" inspired by the tale in an 1845 letter to Poe, even urging the author to "put at rest the growing impression that your account is merely a splendid creation of your own brain, not having any truth in fact" (Ingram 1880, 277). This tendency to read Poe's fiction as a valid case study was of course encouraged by the work itself: Poe's reliance on clinical language and meticulous attention to physical processes, as well as the narrator's insistence that "it is now rendered necessary that I give the facts - as far as I comprehend them myself" (emphasis added, 1233).

In contrast to the abundance of texts surrounding the case of Jahi McMath, the mesmerist's account of E. M. Valdemar stands alone, even as his struggle for narrative authority is both explicitly and implicitly acknowledged. Poe frames the narrator's desire to represent the "facts" as a reaction to a "garbled or exaggerated account" and "many unpleasant misrepresentations" (1233). Poe's tale repeatedly invokes the medical profession: "Valdemar" itself bears the form of a case report and a number of its characters are health care providers. Even the meaningful silences surrounding "Valdemar" affirm the narrator's claim to authority: the competing accounts and "misrepresentations" alluded to by "P" are mere inventions, yet they serve to persuade the reader of the narrator's credibility.

Indeed, "P" continually validates his account through his collaboration with medical authorities, to the extent that he states that the narrative is "for the most part, either condensed or copied verbatim" from the notes taken by a medical student, "Mr. L-l." Basing his narrative on the "memoranda" of this student provides the semblance of dual narration, while still allowing "P" to have the final word - the medical student's impressions remain filtered through the consciousness of the mesmerist.

Beyond the identity of the narrator's imagined source material, patterns of authority within "Valdemar" can be identified by tracing the involvement of the medical community throughout the narrative, gesturing to the implicit tensions between the mesmerist, the physicians, and other providers along the way. The mesmerist is only called to Valdemar's deathbed once his physicians, Doctors "D - and F-," have ceased their ministrations and do not (initially) plan to return: Valdemar's death is imminent, mainstream medical practice has reached its limits. This symbolic departure is only partially undone by the mesmerist, who requests that the physicians return to bear witness to his "experiment." This plan is nearly thwarted by 
Valdemar's illness, the patient is "sinking fast," leaving "P" alone with the nurses. However, "P" refuses to begin until the medical student is in attendance, sparing him "further embarrassment":

A male and female nurse were in attendance; but I did not feel myself altogether at liberty to engage in a task of this character with no more reliable witnesses than these people, in the case of a sudden accident, might prove. (1236)

The mesmerist's medical audience also proves a kind of insurance for his unorthodox investigations. "P" notes that upon their return, the physicians "[oppose] no objection" to the continuation of his work, as well as verify Valdemar's eventual status in "an unusually perfect state of mesmeric trance" (1237-3). When his death is thought to be mere minutes away, the doctors desire that Valdemar remain undisturbed in "his present apparently tranquil condition, until death should supervene" (1239). The narrator's preceding collaboration with the medical profession not only signals his awareness of the fringe status of his discipline but also renders his deviation from sanctioned medical opinion all the more dramatic: he decides to again attempt communication with Valdemar. Disturbing the dying elicits a terrifying physical change: the color disappears from his face, his eyes roll back, and his lower jaw falls with a jerk. Valdemar's appearance is "so hideous beyond conception" that there is a "general shrinking back" of the present company from the bed. Assuming death, "P" and the physicians prepare to entrust the body to the nurses, only to be disrupted by Valdemar himself. "I have been sleeping - and now - now - I am dead" (1240). The medical student faints.

Valdemar's status remains unchanged, and those present discuss the "propriety and feasibility" of attempting to awake him, having

Little difficulty in agreeing that no good purpose would be served by so doing. It was evident that, so far, death (or what is usually termed death) had been arrested by the mesmeric process. It seemed clear to us all that to awaken M. Valdemar would be merely to insure his instant, or at least his speedy dissolution. (emphasis added, 1241)

By his own admission, the mesmerist has challenged previous definitions of death, unveiling some liminal state of the death process that would otherwise go unnoticed. He recognizes that to end the intervention - to awaken or release Valdemar from the trance-would insure his "dissolution." The withdrawal of the senior medical establishment is complete: for the following seven months nurses attend to Valdemar, although what exactly their "attention" entails is not clear.

After supposedly conferring with Valdemar's physicians, the mesmerist decides to "make the experiment ... of awakening or attempting to awaken him," provoking what "P" terms a "(perhaps) unfortunate result" (1241-2). Valdemar's eyes roll back into view accompanied by signs of decay and the mesmerist is unable to direct the movement of Valdemar's limbs, potentially indicating the failure of the body to cooperate with mesmerism. Doctor "F" suggests inquiring what Valdemar's "feelings or wishes [are] now," and the "hideous voice" returns: "For God's sake! -quick! -put me to sleep -or, quick! -waken me! -quick! -I say to you that I am dead!" (1242). The unbalanced power dynamic between patient and practitioner grows increasingly evident as the narrator attempts to revive Valdemar, punctuated by cries of "Dead! Dead!" (1243). While the narrator's expectation to successfully awaken Valdemar is clearly delusional, he is nonetheless shocked by the result: Valdemar's body, released from the effects of mesmerism, rots away, leaving only "a nearly liquid mass of loathsome - of detestable putridity" (ibid.). By yielding control of his body to mesmerism, Valdemar has 
traversed the boundary that separates life and death; science has irrevocably changed the human. This crossing is facilitated by the mesmerist, who has artfully attempted to carve out a place within the medical hierarchy: claiming narrative solidarity with the medical student, disparaging the credibility of the nurses, aligning himself with senior medical professionals ... and eventually placing his "medical" judgement beyond their own.

Of course, Valdemar's remains have the final word among these corroborating and contending opinions. Valdemar's posthumous announcements, while haunting in their ability to break the presupposed silence of death, do not fully afford him decision-making capacity and thus contribute to his depersonalization. In both cases of Valdemar's declarations beyond the grave, Poe focuses on the tongue as the seat of the depersonalized voice, which "vibrates" and "rolls violently" in association with speech. The narrator stresses that Valdemar speaks as if from a distance, and it is that distance between the superficial trappings of life and the grisly reality that so confounds the reader. Defying embodiment, Valdemar's utterances are not performed via the normal apparatus of speech. The body, usually the locus and seat of human experience, is trapped in the grip of opposing forces - the diseased will of the mesmerist and the waiting touch of decay. His pronouncements are dwarfed, in both length and complexity, by the mesmerist's lengthy description of his appearance; the narrator's bodily "reading" of Valdemar as patient overpowers his final attempts to influence his own fate. Nonetheless, his words linger, suspended in the imagination of the reader.

\section{Who speaks? authority and narrative in the case of Jahi McMath}

Undoubtably, the utterances of Jahi McMath following her diagnosis of brain death differ from those of Valdemar. Maintained by machinery despite her devastating neurological injury, she retained the appearance of peace and calm. She did not speak with words, rather her "utterances" were realized through bodily movement. Also in contrast to Valdemar-whose selection for the mesmerist's experiment was in part due to lack of "relatives in America who would be likely to interfere" (1234)—Jahi's family served as fierce advocates; her utterances are both elicited and mediated through her family. These purported declarations of life consist of a series of videos (totaling more than fifty) in which Jahi appears to collaborate with family member's requests. In response to her mother's requests to "move your hand" or "kick your foot," for instance, Jahi appears to reply in kind.

While the performance of volitional movement challenges the notion that Jahi is (brain) dead, it is difficult to determine the true intentionality of her movements - persistent reflexes of the spinal cord can produce such jerks and twitches - and also to measure the contribution of her family's desire for such movement to evidence consciousness. Arian Lewis muses, "Perhaps the movements are spinal reflexes, but selective perception, or wishful thinking, even on a subconscious level, may produce bias causing them to be misinterpreted as purposeful" (2018a, 21). Nonetheless, Alan Shewmon, a retired neurologist and critic of the brain death criteria, finds them convincing, maintaining that they cannot be explained by mere reflex or chance.

Regardless if such movements prove that Jahi is conscious, the videos present momentary bursts of movement against the tragic stillness of over four years. The teenager played a passive role in the evolution of her own story: even as a cacophony of voices swirled around her case, she remained silent, the maintenance of her state dependent on the advocacy of her loved ones. To understand the battle of language surrounding Jahi and to characterize the predominant voices in her case, a brief outline of the events surrounding her death(s) is 
necessary. This "text" of experience can then be understood through the respective "readings" presented by her family as well as the medical, legal, and ethical communities.

In "The Uncommon Case of Jahi McMath," John M. Luce provides a brief overview of the medical details: Jahi "was a 13-year-old obese black girl" who on December 9, 2013, underwent a complex surgery for the treatment of obstructive sleep apnea at Children's Hospital Oakland $(2015,1145)$. While her family commonly implied the procedure was a routine tonsillectomy, the reality was far more complicated, involving a radical removal of tonsillar, pharyngeal, and nasal tissues. After the surgery, and in the presence of her mother, she "started bleeding from her nose and mouth and suffered a cardiopulmonary arrest" (ibid.). She suffered a serious disruption of blood flow to the brain and despite aggressive treatment, did not regain consciousness.

Both a pediatric neurologist and a pediatric intensivist at the hospital declared her to be brain dead, using the accepted medical criteria for pediatric patients (Lewis 2018a, 20). Her family refused to accept the determination, and following a court order ten days later, another pediatric neurologist - from a different institution - confirmed that she met the criteria for brain death. While this is a clinical diagnosis, assessed at the bedside of patients, the family's insistence that she was alive led to further testing, confirming electrocerebral silence and the absence of intracerebral blood flow (ibid.). Legal documents confirm that the family does not dispute the fact that in 2013 their daughter met the criteria for brain death (ibid.). The family's continued efforts resulted in Jahi's release from the California hospital — death certificate in tow. She then underwent a tracheotomy (to facilitate permanent attachment to a mechanical ventilator) and the placement of a gastronomy tube (for artificial nutrition), procedures that the hospital's surgeons had refused, calling them "unethical procedures on a corpse" (qtd. in Paris, Cummings, and Moore 2014, 377). Because Jahi was legally dead in California, she was relocated to New Jersey, which provides for a religious exemption to the determination of brain death. This legislation exists due to the influence of the ultraorthodox Jewish community who insist that per the Hebrew scriptures, only irreversible cardiopulmonary activity is death (Paris, Cummings, and Moore 2014, 376).

For four and a half years, Jahi received "16 hours of in-home care a day from doctors and nurses, paid for by the state's medical insurance” (Swan 2018). Her mother, Nailah Winkfield, quit her job and continued to pay for vitamins and skin care products for her daughter (ibid.). Jahi also received a host of unspecified hormonal supplements, including steroids, in order to maintain vital regulatory functions usually accomplished by the brain. After becoming "sick," her family took her to a hospital in New Jersey, where she underwent exploratory surgery. Her second passingaccompanied by a second death certificate — occurred following this procedure, caused by "bleeding due to liver failure and a brain injury caused by lack of oxygen" (Dolan 2018).

Her family's narrative, which is closely aligned with current litigation, focuses on their denial of Jahi's diagnosis of death, citing her appearance of life as well as their objections on religious grounds. Because brain-death patients show certain signs of life, it is perhaps unsurprising that Jahi's mother initially refused her status as brain dead, stating, "She is warm and soft. She is not cold and stiff like death ... She is not dead. She [just] needs time to get better" (qtd. in Paris, Cummings, and Moore 2014, 376). For Nailah Winkfield, this appearance of life was confirmed by her ability to "feel" her daughter's presence (Dolan 2018). Her intuitions were supported by physicians like Shewmon, who she later considered to have shown that Jahi demonstrated "evidence of a new level of consciousness" (ibid.). In statements, Winkfield has strongly defended her decision to continue Jahi's care, even at the cost of self-described "exile" in New Jersey: 
I knew Jahi wasn't dead ... I'm her mother and I know my child. And I was right. Jahi McMath was not brain dead or any other kind of dead. She was a little girl who deserved to be cared for and protected not called a dead body [sic]. When she finally was treated like a human being she got better. (ibid.)

Winkfield, a professed Christian, insists that Jahi's improvement was a result of her care under "people of faith," as the hospital failed to "step back and let God have some time to heal [her] daughter" (ibid.). When the family's attorney, Christopher Dolan, was criticized in 2013 for giving the family false hope for a "Christmas miracle," his response was to appeal to divine authority, questioning, "Is that unethical? Then is the Church unethical?" comparing the family's expectation of a miracle to the miracles surrounding the birth, life, and resurrection of Jesus Christ himself (Szabo 2014).

Due to such objections, Dolan stated in December 2013 that it was their legal position that "no doctor can make a determination about end of life without parental consent" (qtd. in Luce 2015, 1145). As of December 2018, two lawsuits are currently ongoing: a federal civil rights case to nullify Jahi's original death certificate and a malpractice case against Children's Hospital Oakland. The two cases are inextricably connected, as Jahi's interim status as living or dead would determine how much the family could acquire in monetary damages (Lewis 2018a, 22).

The medical debate surrounding Jahi McMath was typified in a series of articles published in Neurocritical Care, the very titles revealing their competing claims to authority: Ariane Lewis's "Reconciling the Case of Jahi McMath," quickly followed by Shewmon's "Truly Reconciling of Jahi McMath." Lewis stands by the original determination of brain death. Even as she questions if Jahi could be the first person to recover from this state, she stresses that

Physicians have been making determinations of death by neurologic criteria for half a century, so it seems highly improbable that there is something unique about her brain that would allow it to become the only brain that could recover from death. (2018a, 21)

Lewis's article, published mere days before Jahi's final passing and burial, calls for additional testing to see if the criteria for brain death are still met, noting also that such clinical examination had been refused by her family. Until this assessment, Lewis argues, "the discord between the ideas that Jahi is brain dead and that she is following commands cannot be fully reconciled" (22).

Even though Shewmon determined that Jahi met the brain death criteria after performing a physical exam and reviewing studies of brain activity and blood flow, he argues the home videos as evidence that Jahi was alive and intermittently conscious (Lewis 2018a, 523-4). He maintains that Jahi's "apparent responses to command cannot all be explained away as mere chance occurrences," and that a visit to Jahi before she died allowed him to observe these movements firsthand (Shewmon 2018, 167, 169). He insists that Jahi's diagnosis of brain death was a false positive and that she suffered from global ischemic penumbra in which blood flow is "too low to support neuronal function but sufficient to prevent widespread necrosis" (165). This would explain why Jahi's brain failed to liquify - a phenomenon often called "respirator brain"- and why a preservation of some brain structures was observed on MRI. The fact that this condition can "masquerade" as brain death, Shewmon argues, problematizes current criteria for determining brain death (166).

Initial bioethical commentary on the case was marred by unfortunate choices of language: several prominent bioethicists, including Arthur Caplan and Laurence McCullough, referred to 
Jahi as a "corpse." Caplan criticized the family's decision to continue life support, stating that it "makes no medical or normal sense. What's being done to her corpse is wrong ... keeping her on a ventilator amounts to desecration of the body" (2014). McCullough's response was similar, asserting that "there are no ethical issues in the care of someone who is brain-dead, because the patient is now a corpse," as well as challenging the rationality of her family: "Their thinking must be disordered ... There is a word for this: crazy" (qtd. in Szabo 2014). Regrettably, the identification of Jahi as a "corpse" only enhanced public confusion surrounding the case, given the publicized evidence to the contrary.

Later ethical commentary has been more sensitive to the cultural, linguistic, and emotional aspects of the case and especially attentive to the pervasive influence of language. Paris, Cummings, and Moore have suggested that confusion began when physicians first asked the permission of Jahi's family to remove the ventilator, labeling this request as unnecessary and inappropriate: since they maintain brain death as equivalent to death, it "gives a purported choice, when, in fact none exists" $(2014,380)$. Opening the door to greater emotional turmoil may "result in a decision to continue medical intervention in the hope of a miracle. Once an appeal to higher authority or divine power has been made, continued discussion of the patient's medical status is nugatory" (ibid.). Commentators have also gestured to the ambiguity suggested by the term "brain dead," suggesting that the use of "brain" to describe death is unnecessary and confusing: brain death is death.

Who has the epistemological authority to decide the "facts" of Jahi's story? Winkfield claims that by her position as a parent, she can endorse or reject medical diagnoses. Her family claimed divine healing and waited expectantly for a miracle. Years after the public relation representative of the hospital, Sam Singer, accused Christopher Dolan of "perpetuating a tragic hoax on the public as well as misleading the family," (qtd. in Luce 2015, 1146) Winkfield dismissed his suggestion of exploitation as a "racist narrative," stating "I'm not stupid, I was right. I probably know more about medicine after these four and a half years than most medical students" (Dolan 2018). If we are to take Winkfield at face value, that understanding could make her just as suited as "Mr. L- l" for recording the "facts" of the story. While a medical reading of Jahi's condition offers some measure of objectivity, a lack of interpretive agreement remains. We glimpse but "through a glass darkly" at brain death criteria and the associated legal constructs. The relationship between the spectrum of biology, the practicality of bioethics, and the weight of the law remains blurred.

The intention of the mesmerist, then, is one ultimately shared by the reporters, physicians, ethicists, lawyers, and family members who continue to vie for textual authority over Jahi's story: to "give the facts - as far as I comprehend them myself" (Poe 1987, 1233). And yet, both narratives are marked by an uncomfortable inscrutability; Jahi's story in particular remains opaque to standard definitions of death, highlighting the complex biological, social, and cultural realities underpinning these classifications.

\section{Defining death}

In his chapter on "Brain Death" in The Routledge Companion to Bioethics, Winston Chiong begins with the following quote from Poe's short story, "The Premature Burial": "the boundaries which divide Life from Death are at best shadowy and vague. Who shall say where the one ends, and where the other begins?" (qtd. 2015, 462). J. Gerald Kennedy has noted that "Valdemar" presents a dramatization of "the scientific effort - taken in the eighteenth century 
and continuing in our era of medical technology - to understand, control, and perhaps conquer the major causes of death" $(1987 \mathrm{~b}, 131,132)$. Indeed, the technological and medical advances of the eighteenth century transformed the corpse into an object of anatomical study and reconceptualized death as an exclusively physiological process (114). The rising scientific medicine represented death and life as "mutually defining opposites," with death being merely the absence of life (Stern 2008, 347). Within such a binary, the idea of undeath, inclusive of the liminal state of M. Valdemar or even of Jahi McMath, is implicitly discredited (ibid.). The role of the church in the process of death also gradually diminished over the eighteenth century, leading to the appearance of public cemeteries during this period (Kennedy 1987b, 114). Definitions of death have continued to change well into the twentieth century, likely indicative of a decentered and increasingly secular culture. Still, these shifting considerations have "failed to mitigate or resolve the underlying dread" of death (Kennedy 1987a, 131).

Prior to the latter half of the eighteenth century, physicians did not play a major role in pronouncing death. Instead, recognition of death was left to the caregivers of the deceased, typically family members (Chiong 2015, 462). However, the development of life-saving technology such as electrical resuscitation sparked doubts regarding this boundary, concerns that eventually erupted into widespread fear of premature burial (Chiong 2015). Physicians responded with more precise ways of observing death, and the 1819 invention of the stethoscope provided the means to forge a consensus: a lack of circulatory and respiratory activity indicated a lack of life (ibid.).

The twentieth century witnessed a myriad of biomedical advances, particularly the advent of intensive care (most notably artificial respiration) and organ transplantation. Understandably, this caused an erosion of circulatory definitions of death, as an individual with total brain failure would otherwise be considered alive on life support. The rise of organ transplantation further complicated this dilemma: would taking organs from a "brain dead" patient on artificial respiration be tantamount to harvesting organs from a living donor? While the eighteenthcentury fear of being buried alive had long faded, fears of having one's organs removed while still alive surfaced in response to this impasse.

Amid this uncertainty, a 1968 Ad Hoc Committee of the Harvard Medical School determined new criteria for pronouncing death: irreversible coma due to loss of all brain function (“A Definition of Irreversible Coma" 1968, 340). These neurologic criteria were quickly adopted throughout the United States and much of the Western world. Despite the fact that a (correctly diagnosed) brain-dead individual has no chance of meaningful recovery, controversy and unease persisted. A brain-dead individual on life support may deceptively appear to be living due to the suspension of decomposition: such individuals are warm to the touch, and their chests rise and fall as if breathing independently (Chiong 2015, 468). Moreover, Shewmon has memorably reported cases of brain death in which patients demonstrated a "litany" of functions not mediated by the brain: proportional growth (in children), sexual maturation, gestation of a fetus, and the fighting of infections, among others (2001, 466-467). He notes that Jahi herself experienced "three menstrual periods" in 2014, as well as the development of secondary sexual characteristics $(2018,168)$.

Even so, most continue to support the conception of brain death as death; an overwhelming number of medical organizations recognize death as an "irreversible loss of consciousness and brainstem function leading to the inability to breathe independent of artificial support," the definitive "demise of every neuron ... is not required" (qtd. in Lewis 2018b, 523). Others have advocated for a return to circulatory-respiratory definitions or promoted a higher-brain criterion, where permanent unconsciousness alone signals one's passing (Chiong 2015, 463). The 
2008 US President's Council on Bioethics supported the whole-brain criteria, defining death as the loss of an organism's ability to perform its "fundamental vital work" (60). Whereas a full consideration of these competing frameworks is outside the aims of this paper, it is necessary to note that an individual considered alive by one definition can be easily considered dead by another.

Part of this difficulty arises in the conflation of legal and biological definitions of death. In "Defining Death-Making Sense of the Case of Jahi McMath," Robert D. Truog seeks to "make sense" of something that-perhaps contrary to the expectations of the medical community — cannot be fully reconciled. Brain injury exists on a spectrum, with brain death inhabiting the bottom of that range: a loss of "most—but not necessarily all" brain function (2018, 1859). The Uniform Determination of Death act draws a "bright line" at brain death, rendering those functioning below that cutoff legally dead. Truog suggests that the "failure to appreciate the difference between bright legal lines and the continuous spectrum of biological functioning" (1859) perpetuates confusion in Jahi's case. However, the recognition that sharp legal boundaries serve as social constructs does not completely resolve the inherent strangeness of the McMath case.

Caught between such definitions, constructs, and continuums, Megan Stern notes that undead bodies "highlight other borderlines between mind and body, subject and object, reason and emotion, knowledge and belief, professional expertise and popular opinion" (2008, 347). Poe's fiction and contemporary debates surrounding death present similar queries: what is the difference between the death of an organism and the death of a person? Can the death of a person occur without the death of his or her body? The true significance of human death - in its biological, philosophical, and theological implications-remains opaque.

\section{Resisting textual closure}

If both narratives challenge the binaries of life/death and fact/fiction, they also gesture to the relationship between storytelling and death. James M. Hutchisson has noted this relationship in Poe's work, stating:

But most important of all, to Poe, is the reciprocal relationship between storytelling and life, or between textual closure and death. After all, Poe's abiding concern throughout his life and literary career was to understand the nature of death. His characters perpetually devise ways of experiencing death yet not dying, of losing loved ones yet somehow reclaiming them from the hereafter. Storytelling is an interminable, never-tobe-completed project that invisibly alters the author's relationship to death. $(2011,42)$

The accounts of both Valdemar and Jahi McMath present individuals who find means of “experiencing death yet not dying" (Hutchisson 2011, 42). While Valdemar's life ends within the pages of "Valdemar," his declarations from beyond the grave resist textual closure. The post-publication disputation of this story allows for an extension of Valdemar's (fictitious) life; a tale of death paradoxically promotes the "life" of its subject. Similarly, as Jahi's family clung to a narrative that assumed she was alive, she retained a foothold, however tenuous, among the living. Both stories are haunting in their lack of closure; their respective narratives offer a manner of (textual) immortality, even as they reaffirm the inscrutability of loss.

It is impossible to render Poe's "Valdemar" equivalent to any real-life situation: this is a sensationalist fiction, unambiguously designed to invoke fear and terror in the reader. These 
emotions are instructive, however, especially when "Valdemar" is recognized as a cautionary tale of the murky ethical and biological territories opened by the (mis)use of medical technology. To dismiss mesmerism as mere antebellum fad or pseudoscience misses the core of Poe's imaginative experiment: "Valdemar" anticipates the darker implications of our everadvancing medical technology, namely its ability to transform human capability and so blur the lines between life and death, fact and fiction.

Poe's tale demands that we not only take account of the ways technology influences the human but also that we take responsibility for our creation of liminal states of undeath. Interpretations of cases such as "Valdemar" or that of Jahi McMath necessarily carry an ethical dimension, and our "readings" of such narratives bear both philosophical and practical implications. What is death? What is our responsibility to those who subsist in states of undeath? How can the medical and bioethical community respond to these situations in a way mindful of patients' individual narratives, their inherent dignity, and the quality of the life that they do-or do not-experience?

While answering these questions rests beyond of the scope of this paper, both Jahi McMath and Ernest M. Valdemar provide case studies for the aggressive application of life support that renders such care tantamount to "death support." The disagreement inherent to and proceeding both narratives highlights the need for epistemological humility, as well as the recognition that no particular view of a narrative - whether it be personal, literary, scientific, or philosophicalis sufficient in isolation. Multidisciplinary approaches become even more important given the relative silence of the individuals inhabiting the core of these stories, as well as our duty to attend to their posthumous utterances.

Crucially, both narratives influence the meaningful gaps in our own vocabularies of death. Recognizing that the diagnosis of death by neurologic criteria is embedded in a complex cultural, medical, and legal landscape affirms the need for a "language of death and dying" that can accommodate, or at least mitigate, the ambiguities surrounding death in our technological age, and do so with candor and empathy. The more sophisticated our attempts to control our mortality, the more resistant these shadowy boundaries become. Both Poe's "Valdemar" and the case of Jahi McMath give us a glimpse, however dim, into these unknown regions.

\section{References}

A Definition of Irreversible Coma. 1968. Report of the Ad Hoc Committee of the Harvard Medical School to Examine the Definition of Brain Death. JAMA 205 (6): 337-340.

Caplan, Arthur. 2014. "Caplan: The Case Against Care for Those Who are Brain Dead." Newsday. Accessed 17 March 2017. https://www.newsday.com/opinion/oped/caplan-the-case-against-care-for-those-who-are-braindead-1.6767446.

Chiong, Winston. 2015. "Brain Death.” In The Routledge Companion to Bioethics, edited by John D. Arras, Elizabeth Fenton, and Rebecca Kukla, 462-473. New York: Routledge.

Dolan, Christopher. 2018. "Jahi McMath has Died in New Jersey." Dolan Law Firm. Accessed 20 December 2018. https://dolanlawfirm.com/2018/06/jahi-mcmath-has-died-in-new-jersey/.

Hutchisson, James M. 2011. "Storytelling, Narrative Authority, and Death in 'The Thousand and Second Tale of Scheherazade." In Edgar Allan Poe: Beyond Gothicism, edited by James M. Hutchisson, 37-48. Newark: U of Delaware.

Ingram, John H. 1880. Edgar Allan Poe: His Life, Letters, and Opinions. London: John Hogg Kennedy. Kennedy, J. Gerald. 1987a. "Metamorphoses of the Shadow." In Poe, Death, and the Life of Writing, 177-214. New Haven: Yale UP. 
1987b. "Phantasms of Death in Poe's Fiction." In The Tales of Poe (Modern Critical Interpretations), edited by Harold Bloom, 111-133. New York: Chelsea House.

Lewis, Ariane. 2018a. "Reconciling the Case of Jahi McMath." Neurocritical Care 29:20-22. 2018b. "Response to Machado et al. re: Jahi McMath." Neurocritical Care 29:523-524.

Lind, Sidney E. 1947. "Poe and Mesmerism." PMLA 62: 1077-1094.

Luce, John M. 2015. "The Uncommon Case of Jahi McMath.” Chest: Medical Ethics 147 (4): 1144-1151.

Mills, Bruce. 2013. "Mesmerism." In Edgar Allan Poe in Context, edited by Kevin J. Hayes, 322-331. Cambridge: Cambridge UP.

Paris, John J., Brian M. Cummings, and M. Patrick Moore. 2014. “'Brain Death,' 'Dead,' and Parental DenialThe Case of Jahi McMath.” Cambridge Quarterly of Healthcare Ethics 23 (4): 371-382.

Poe, Edgar Allan. 1856. "The Man That Was Used Up." In The Works of the Late Edgar Allan Poe, edited by Rufus Wilmot Griswold, 315-325. New York: Renfield.

_. 1978. "The Facts in the Case of M. Valdemar." In Collected Works of Edgar Allan Poe, Volume III: Tales and Sketches 1843-1849. Edited by Thomas Ollive Mabbott, 1233-1243. Cambridge, MA: Belknap Press.

Shewmon, Alan. 2018. "Truly Reconciling the Case of Jahi McMath.” Neurocritical Care 29: 165-170.

2001." The Brain and Somatic Integration: Insights into the Standard Biological Rationale for Equating Brain Death with Death." The Journal of Medicine and Philosophy 26 (5): 457-478.

Stern, Megan. 2008. "'Yes: - No: — I Have Been Sleeping_And Now-now-I Am Dead': Undeath, the Body and Medicine." Studies in History and Philosophy of Science Part C: Studies in History and Philosophy of Biological and Biomedical Sciences 39 (3): 347-354.

Swan, Rachel. 2018. "Jahi McMath to be Buried in Hayward while Fight over her Death Continues." SFGATE. Accessed 3 July 2018. https:/www.sfgate.com/bayarea/article/Family-of-Jahi-McMath-gets-approval-tobury-their-13047928.php.

Szabo, Liz. 2014. "The Ethics of Being Brain Dead: Doctors and Bioethicists Discuss Jahi McMath and Marlise Munoz." Huffington Post. Accessed 17 March 2017. https://www.huffingtonpost.com/2014/01/10/ethicsbrain-dead_n_4577116.html.

The President's Council on Bioethics. 2008. "The Philosophical Debate." In Controversies in the Determination of Death: A White Paper by the President's Paper on Bioethics, 49-68. Washington DC.

Townshend, Chauncy Hare. 1841. Facts in Mesmerism or Animal Magnetism: With Reasons for a Dispassionate Inquiry Into It. Boston: Charles C. Little and James Brown.

Tresch, John. 2016. "'Matter No More': Edgar Allan Poe and the Paradoxes of Materialism." Critical Inquiry 42 (4): 865-898.

Truog, Robert D. 2018. "Defining Death-Making Sense of the Case of Jahi McMath.” JAMA 319 (18): 18591860.

Willis, Martin. 2006. "The Human Experiments of Edgar Allan Poe.” In Mesmerists, Monsters, and Machines: Science Fiction and the Cultures of Science in the Nineteenth Century, 94-132. Kent, OH: Kent State UP.

Publisher's Note Springer Nature remains neutral with regard to jurisdictional claims in published maps and institutional affiliations. 